\title{
Um Sistema Multiagente para Identificar Falhas na Conversação no Bate-papo da CV-Muzar
}

\author{
Ana Carolina Bertoletti De Marchi ${ }^{1}$, Roberto dos Santos Rabello ${ }^{1}$, Afonso \\ Alban $^{1}$, Juliano Mauricio Bordignon ${ }^{1}$, Liliana Passerino ${ }^{2}$ \\ ${ }^{1}$ Curso de Ciência da Computação - UPF, Caixa Postal 611 - 99010-970 - Passo \\ Fundo (RS) - Brasil \\ \{carolina, Rabello, 97528, 83485$\}$ @upf.br \\ ${ }^{2}$ Programa de Pós-Graduação em Informática na Educação - UFRGS, Av. \\ Paulo Gama, 110 - prédio 12105 - $3^{\circ}$ andar - 90040-060 - Porto Alegre (RS) - \\ Brasil \\ liliana@cinted.ufrgs.br
}

Resumo. Este artigo apresenta o Sistema Multiagente (SMA) proposto para monitorar a conversação no bate-papo da Comunidade Virtual do Muzar (CVMuzar). Para tanto, são analisados os marcadores conversacionais e sua aplicação em ambientes de conversação síncrona, com vistas a propor mecanismos de compensação para os déficits de comunicação identificados. $O$ SMA proposto conta com cinco agentes cooperativos que monitoram as conversas em tempo real e interferem na interface de conversação para aconselhar e, se necessário, advertir o participante.

Palavras-chaves: Sistema Multiagente. Agentes Inteligentes. Comunidades Virtuais.

Abstract. This article shows a Multiagent System (MAS) proposed to monitor conversations in the chat tool of the Muzar Virtual Community (Comunidade Virtual do Muzar, CV-Muzar). Thus, conversational markers and their use in synchronous chat environment are being analyzed to propose a compensation mechanism for the identified communication deficits. The proposed MAS has five cooperative agents that monitor conversations in real time and interfere with the chat interface to advice and, if necessary, warn the participant.

Keywords: Multiagent System. Intelligent Agents. Virtual Community.

\section{Introdução}

A busca por novas dimensões de construção do conhecimento, representada pela interação virtual, motivou o desenvolvimento de um novo espaço de interação para o Museu Zoobotânico Augusto Ruschi (Muzar). 
Desde 2005, o Muzar conta com uma Comunidade Virtual de Aprendizagem (CV-Muzar) projetada para envolver cada vez mais o visitante e torná-lo cúmplice da experiência vivenciada, procurando, com isso, acabar com o destinatário passivo do discurso expositivo que se estabelecia unilateralmente, oferecendo aos visitantes um espaço de encontros e convivências, rompendo fronteiras geográficas e temporais (De Marchi 2006).

$\mathrm{Na} \mathrm{CV}$-Muzar o visitante virtual tem acesso a um conjunto de recursos de aprendizagem e condições facilitadas para: a) a experimentação virtual; b) a construção de problemas/soluções; c) o compartilhamento de ideias; d) a construção do acervo junto aos profissionais; e) a formação de discussões intelectuais. Para tanto, são oferecidas ao visitante várias ferramentas, dentre as quais se destaca o bate-papo.

Os bate-papos vêm proporcionando o surgimento de novas formas de sociabilidade, onde indivíduos se aglutinam em torno de interesses comuns, independente das distâncias espaciais. A conversação é um elemento básico da comunicação humana e essencial nas interações sociais das comunidades virtuais, por meio da virtualização da linguagem.

Para que haja a troca comunicativa em uma conversação, não basta que dois ou mais indivíduos falem de forma alternada, é preciso que todos os participantes estejam envolvidos na troca e engajados com o processo, recorrendo aos diversos procedimentos de validação interlocutória. Os cumprimentos, as apresentações, as saudações e outros rituais desempenham um papel importante, mas a validação interlocutória se consolida por meios importantes como o emissor, o receptor e a sincronização interacional.

A comunicação através da interação face a face é um processo inteiramente colaborativo e que pode ser prejudicado pela unilateralidade ou desconsideração de um dos elementos citados. Nesse contexto, a conversação é um dos elementos da comunicação aonde os interlocutores podem interagir e efetuar trocas de conhecimentos que acabarão normalmente no resultado cognitivo (Rabello, 2008).

Uma conversação não bem sucedida pode caracterizar dificuldades de sociabilização dentro de uma comunidade, gerando, muitas vezes, interpretações equivocadas. Igualmente, tais interpretações podem ferir, pelo menos, três dos doze princípios das comunidades virtuais apontadas por Mongoose (2001), a saber: i) a reputação; ii) a comunicação; e iii) a confiança entre os participantes.

Durante uma conversação, os marcadores são importantes para garantir a fluência, a lógica e a compreensão do processo comunicativo. Estes marcadores são palavras ou expressões bastante estereotipadas. Eles aparecem no contexto geral, particular ou pessoal da conversação, e não dependem especialmente de novas informações para o desenvolvimento do tópico (Marcuschi, 2006).

Nesse sentido, diante da importância da comunicação para a interação social em uma comunidade virtual, bem como da importância da interação social para o desenvolvimento cognitivo, busca-se, com este trabalho, propor um sistema multiagente que auxilie na identificação de falhas no uso dos marcadores verbais nos bate-papos realizados na CV-Muzar. Tal método visa propor mecanismos de 
compensação para os déficits de comunicação identificados. Com isso, é possível uma maior evolução e fluência nos diálogos, uma participação mais efetiva dos envolvidos no chat e, consequentemente, um melhor resultado no que diz respeito à interação e ao desenvolvimento cognitivo dos visitantes do Muzar.

\section{A Comunicação em uma Comunidade Virtual}

A conversação é um elemento básico da comunicação humana, que se caracteriza pela participação de pelo menos dois sujeitos numa situação de diálogo, ou seja, com existência de trocas entre os falantes. Marcuschi (2006) identifica 5 características essenciais: (1) interação entre pelo menos dois falantes; (2) ocorrência de pelo menos uma troca entre os falantes; (3) presença de uma seqüência de ações coordenada; (4) execução numa identidade temporal; (5) envolvimento numa interação centrada.

Conversação é uma interação verbal centrada, que se desenvolve durante o tempo em que dois ou mais interlocutores voltam sua atenção visual e cognitiva para uma tarefa comum (Marcuschi, 2006, p.15).

De acordo com Watzlawick, Beavin e Jackson (2000), todo o comportamento, numa situação interacional, tem valor de mensagem, ou seja, é comunicação, isso indica que, por mais que o indivíduo se esforce, é impossível não comunicar. Ainda, de acordo com estes autores, até a própria inatividade ou o silêncio agregam a eles um valor de mensagem. Todavia, não se pode dizer que a comunicação só acontece quanto existe intencionalidade, ou quando é consciente ou bem sucedida, isto é, quando ocorre uma compreensão mútua.

Para que haja troca comunicativa, não basta que dois ou mais indivíduos falem de forma alternada, é preciso que todos os participantes estejam envolvidos na troca e engajados com o processo, recorrendo aos diversos procedimentos de validação interlocutória. Os cumprimentos, as apresentações, as saudações e outros rituais desempenham um papel importante, mas a validação interlocutória se consolida por meios importantes (Orecchini 1996), são eles: a) o emissor; b) o receptor; c) a sincronização interacional, que se identifica, principalmente, pelo funcionamento dos turnos de fala, comportamentos corporais dos participantes da interação, escolhas dos temas, registro de troca, entre outros.

Toda a conversação é situada em algum contexto. O discurso é uma atividade condicionada pelo contexto e que o transforma ao mesmo tempo. Entre os materiais existentes numa conversação estão: o material verbal, o paraverbal e o não-verbal. Os não-verbais podem ser relacionados com aspectos físicos dos participantes como etnias, roupas, acessórios, sexo; com os aspectos cinéticos lentos como distâncias, atitudes e posturas e com os aspectos cinéticos rápidos como olhares, mímicas e gestos. O material verbal além de ser parte do conteúdo do discurso também pode ter funções para restaurar o dialogo, compensar falhas, manter a atenção do ouvinte, conservar turno, ou seja, manter e delimitar o contexto. Esse tipo de material verbal é denominado de marcador verbal, que são um tipo especial de marcadores conversacionais. Marcadores conversacionais são elementos na conversação que organizam e estruturam a 
conversação permitindo a troca de turnos, a junção de idéias, entre outras funcionalidades (Marcuschi, 2006).

A comunicação é central para a interação social e esta pode interferir significativamente no desempenho escolar, no profissional ou na comunicação social. Quando o indivíduo se comunica, permite ao outro que conheça seus pensamentos, sentimentos, necessidades e passa a conhecer os sentimentos, os pensamentos e as necessidades do outro. Podemos nos comunicar com o outro escrevendo, dizendo, representando ou mesmo gesticulando. Todas estas formas de comunicação podem ser agrupadas, por alguns estudiosos, no comportamento verbal e constituem uma aquisição recente da espécie humana.

Nos dias atuais, além da leitura, da escrita, da fala e dos gestos, contamos com um novo espaço comunicacional, que desestabilizou os modos tradicionais de comunicação e trouxe processos provocadores de rupturas, como a interatividade, o inter-relacionamento de conhecimentos, numa relação nova de conceitos: de contexto, de espaço e de tempo das mensagens entre autores e leitores. Esse novo espaço caracteriza-se como a comunicação que se dá entre seres humanos através da instrumentalização de computadores, denominado por Herring (1996) como Comunicação Mediada por Computador (CMC). A CMC pode ocorrer em diversas modalidades, tais como: textual, gráfica, auditiva e visual. Neste trabalho iremos nos deter na CMC baseada em textos. Os participantes da CV-Muzar interagem através da palavra escrita, digitando mensagens que são simultaneamente lidas por outras pessoas em suas respectivas telas de vídeo - CMC síncrona (chat).

Nos chats (também denominados salas de bate-papo) a comunicação é dinâmica, interativa e síncrona. Esse sincronismo possibilita que pessoas geograficamente distantes dialoguem em tempo real, o que proporciona que sejam estabelecidas relações com um grande número de pessoas ao mesmo tempo. $\mathrm{O}$ chat pode simular um diálogo oral que é na verdade escrito de modo oralizado e, na grande maioria das vezes, coloquial. Segundo Doell em Recuero (2002), o chat apresenta uma linguagem híbrida, que possui características tanto da linguagem escrita quanto da linguagem oral.

Os chats virtualizam elementos da oralidade e da escrita com a possibilidade de utilizar sinais que auxiliam os outros a interpretar aquilo que foi dito, acrescentando emoções. Através desse canal de interação mútua, os interagentes constroem uma relação entre si; debatem diferentes temas em uma velocidade que pode se aproximar de um encontro face-a-face; negociam o encaminhamento da interação e possivelmente criam suas próprias regras. No diálogo on-line pode-se encontrar uma linguagem mais informal e cheia de particularidades, como o uso de abreviaturas (ex: blz = beleza, vc = você, $\mathrm{rs}=$ risos, $\mathrm{tc}=$ teclar $)$, uso de letras minúsculas e maiúsculas de acordo com a intenção do "falante". A objetividade e a rapidez são elementos básicos. Outras particularidades como a conversa ser compartilhada com todos ou não (reservadamente) está presente na utilização dos chats como ferramenta de comunicação.

Os chats, juntamente com as demais modalidades de CMC, vêm proporcionando o surgimento de novas formas de sociabilidade, onde indivíduos se aglutinam em torno de interesses comuns, independente das distâncias espaciais. Para Lévy (1996, p.20), a 
virtualização da linguagem reinventa uma cultura, atingindo até mesmo as modalidades do estar junto, o que fez surgir novos meios de interações sociais como as comunidades virtuais $(\mathrm{CV})$. Para o autor, uma comunidade virtual "vive sem lugar de referência estável, em toda a parte onde se encontrem seus membros móveis... ou em parte alguma”.

Na CV-Muzar, por priorizarmos a comunicação para a interação social, muitas funcionalidades foram automatizadas com o uso de agentes inteligentes e os marcadores conversacionais são elementos fundamentais para o reconhecimento de interação sem precisar abordar o problema da linguagem natural. Desta forma, este artigo irá apresentar a estrutura de agentes projetada para auxiliar na conversação on-line, por meio dos marcadores conversacionais.

\section{Marcadores Conversacionais}

Marcadores são palavras ou expressões bastante estereotipadas. Eles aparecem no contexto geral, particular ou pessoal da conversação, e não dependem especialmente de novas informações para o desenvolvimento do tópico. De acordo com Marcuschi (2002), existem relações estruturais e linguísticas entre a organização da conversação em turnos e a ligação interna em unidades constitutivas de turno. Os marcadores do texto possuem funções tanto conversacionais quanto sintáticas e podem ser divididos em três categorias: verbais, não-verbais e supra-segmentais.

Os não-verbais, tais como o riso, o olhar e franzimento da testa, ocupam um lugar importante na interação face a face e têm a função de estabelecer, manter e regular o contato. Já os supra-segmentais são de natureza lingüística e não-verbal. São as pausas e o tom de voz.

Finalmente, os marcadores verbais podem ser divididos em duas categorias que são sinais do falante e sinais do ouvinte. E cada um deles pode ter funções conversacionais e funções sintáticas. As funções conversacionais são consideradas sob dois aspectos: a) sinais produzidos pelo falante, que, geralmente, servem para manter o turno; b) sinais produzidos pelo ouvinte, que funcionam dentro do turno de um interlocutor e, muitas vezes em sobreposição, servem para dar orientação ao falante em relação à recepção.

As funções sintáticas podem se responsabilizar não somente pela sintaxe da interação, mas, também, pela segmentação e pelo encadeamento de estruturas linguísticas, o que pode provocar uma forte relação entre a sintaxe da interação e a gramatical.

Quanto às posições, os sinais do falante podem vir tanto no início, desenvolvimento ou final de turno, enquanto o ouvinte vem, normalmente, no ponto de discordância ou concordância com os sinais do falante e, normalmente, se localiza no desenvolvimento do diálogo.

Para estabelecer uma conversação síncrona no bate-papo, duas ou mais pessoas devem partilhar um mínimo de conhecimento em comum, onde toda a conversação aconteça mediante a alguma circunstância ou contexto em que os participantes estão envolvidos. Segundo Marcuschi (2002), o mais comum é que uma conversão tenha pelo 
menos três seções distintas estruturalmente, ou seja, uma abertura, um desenvolvimento e um fechamento.

A importância dos marcadores é fundamental na construção de coerência e coesão da conversação, pois podem funcionar como iniciadores de turno ${ }^{2}$ ou unidade comunicativa, ou como finalizadores, funcionando como articuladores e determinando as expressões de interação entre os interlocutores.

Especialmente interessante são os marcadores verbais, pois estes podem ser lexicados, ou seja, compostos por palavras como "sabe?"; "eu acho que"; ou, então, não-lexicados com expressões do tipo "ahn", "eh" etc. Os não-verbais podem ser as pausas mais alongadas e as ênfases em frases ou sílabas para demarcação.

$\mathrm{Na}$ questão semântica, a maioria desses marcadores não apresenta nenhuma importância para o entendimento do texto, mas, às vezes, expressões como "eu acho que" e "eu tenho a impressão" que não contribuem efetivamente para o desenvolvimento do tópico conversacional (assunto), tem como função revelar um ponto de vista do falante ou testar o grau de atenção do ouvinte ${ }^{3}$. Os sinais conversacionais podem ser observados no quadro de Marcuschi (2002) (Figura 1).

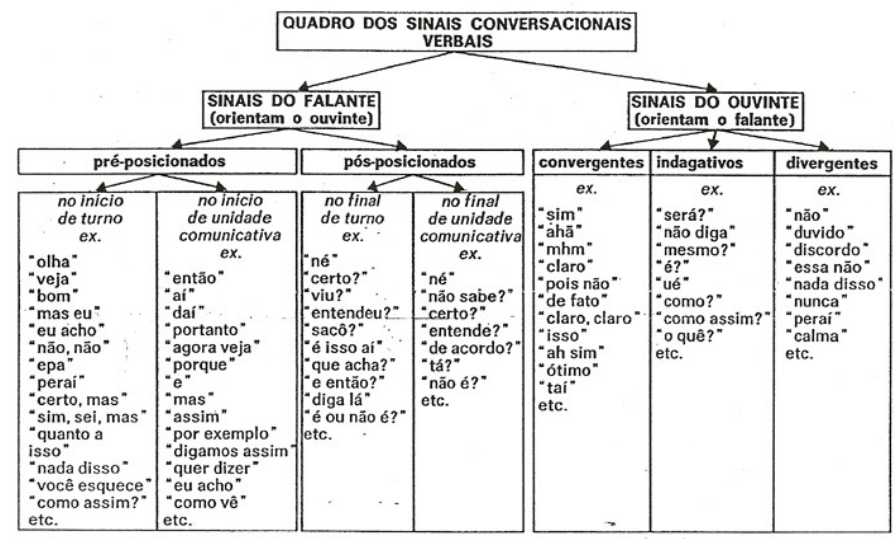

Figura 1. Sinais conversacionais verbais - Fonte: Marcuschi $(2002$, p. 71)

Com base na Figura 1, e nos conceitos vistos até agora, é possível relacionar funções, formas e posições, como disposto nos itens abaixo (Marcuschi 2002):

- sinais de tomada de turno: são expressões utilizadas para se identificar início ou tomada de turno, como, por exemplo: "olha", "veja", "bom", etc;

- sinais de sustentação de turno: utilizados, normalmente, pelo falante para manter a posse do diálogo, retomar ou obter a atenção do ouvinte. Normalmente, aparecem no

2 A ideia de turno está ligada às várias situações em que os membros de um grupo se alternam ou se sucedem na consecução de um objetivo comum. Assim, na análise da conversação, podemos entender turno como aquilo que um falante faz ou diz enquanto tem a palavra, incluindo também a possibilidade de silêncio. $O$ turno se trata de qualquer intervenção do interlocutor (Marcuschi, 2002).

As funções dos marcadores podem ser mais genéricas, como de articuladores e estruturadores ou mais específicas de monitoramento do ouvinte, da busca de aprovação, sinalizadores de hesitação, de atenuação ou de reformulação além da intenção e interação do falante.

V. $7 \mathrm{~N}^{\mathrm{o}}$ 3, dezembro, 2009 
final de uma unidade comunicativa e na forma de indagação como "acha?", "né?", "ta", etc;

- sinais de saída ou entrega de turno: estes sinais aparecem no final de turno com o objetivo de repassar o diálogo do falante para o ouvinte, invertendo os papéis. Normalmente, aparecem na forma indagativa, aguardando na sequiência do outro;

- sinais de armação do quadro tópico: utilizados para sinalizar em que ponto se encontra a conversação, como, por exemplo: "agora que já conversamos sobre isso, podemos falar sobre o tempo";

- sinais de convergência ou divergência: são sinais que, normalmente, aparecem como sobreposição de turno e servem para demonstrar que o ouvinte está prestando atenção ou até mesmo concordando com o falante;

- sinais de abrandamento: normalmente, aparecem como forma de atenuar a transmissão de notícias desagradáveis com a intenção de minimizar riscos.

Estes conceitos abordados sobre os sinais conversacionais verbais dão um embasamento para o entendimento dos marcadores conversacionais, importantes para uma análise da conversação e para o objetivo deste trabalho.

\section{O Sistema Multiagente do Chat da CV-Muzar}

O termo "agente" é mais aceito pela comunidade científica como um programa de software que auxilia o usuário na realização de alguma tarefa ou atividade (Wooldridge 2002), sendo dotado de inteligência e autonomia. A autonomia, neste caso, significa que cada agente possui sua própria existência, operando sem a intervenção de humanos ou outros agentes e tem controle sobre suas ações e seu estado interno.

Quando existem vários agentes num mesmo ambiente interagindo constitui-se um Sistema Multiagente (SMA). O SMA é formado quando há a intenção de alcançar um objetivo em comum com a ajuda de vários agentes operando no ambiente. Em um SMA a comunicação é fundamental para permitir que haja colaboração, negociação e cooperação entre entidades independentes. Em sistemas multiagentes é necessário que a comunicação seja disciplinada para que os objetivos sejam alcançados efetivamente e eficientemente, necessitando assim uma linguagem que possa ser entendida pelo outros agentes presentes no ambiente. Essa comunicação tem como principal objetivo à partilha do conhecimento com os outros agentes e a coordenação de atividades entre agentes, ou seja, ela deve permitir que agentes troquem informações entre si e coordenem suas próprias atividades sempre em um sistema coerente.

No chat da CV-Muzar está sendo implementado um Sistema Multiagente (SMA), o qual consiste em cinco agentes cooperativos para a análise dos diálogos entre os participantes da comunidade nas salas de bate-papo. As conversas são monitoradas em tempo real com o objetivo de identificar possíveis déficits no diálogo como, por exemplo, entradas e saídas de turnos. Nesse caso, os agentes que compõem o sistema podem interferir na interface de conversação para aconselhar e, se necessário, advertir o participante, conforme suas funções, a seguir descritas: 
- AgenteUm: responsável pela solução de problemas simples; como a falta de saudações no início de uma conversa e o controle de tempo entre os turnos do usuário falante e o usuário ouvinte.

- AgenteDois: responsável por uma verificação mais complexa das frases, como, por exemplo, ausência de marcadores de início e final de turno e pontuação. Inicia suas ações ao receber uma confirmação do AgenteUm. Para a análise dos marcadores, utiliza-se a tabela sugerida por Marcuschi (2002), onde há uma lista de marcadores pré e pós-posicionados do falante (primeiro turno, que orientam o ouvinte); e uma série de sinais indicadores de convergência, indagação ou divergência usados pelo ouvinte (turno subsequente, que orientam o falante).

- AgenteTres: encarregado de interferir no chat - como se houvesse um terceiro usuário. O AgenteTres adverte sobre as falhas que o usuário cometeu e deve observar a coerência da conversa; e, se necessário, confirmar alguma verificação que não coincidiu com nenhuma ocorrência cadastrada no banco de dados de marcadores. $\mathrm{O}$ agente interfere sobre o diálogo se alguns destes casos acontecer:

- um usuário não iniciar uma sessão sem as devidas saudações pessoais do tipo oi, olá, bom dia, boa tarde, boa noite, tudo bem, entre outros;

- o usuário ficar durante um tempo considerável sem interagir com os demais participantes;

- na conversa houver palavras inadequadas vindas de algum dos usuários;

- caso haja três participantes e o destinatário comum entre duas pessoas for o mesmo, assim não está ocorrendo uma interação completa entre os participantes;

- no caso da falta de uso de marcadores.

$\mathrm{O}$ agente, ao perceber tais características vindas do ambiente, fará o processamento necessário e agirá de forma pouco intrusiva, apenas orientando os participantes do diálogo como um tutor ou mesmo propondo técnicas de compensação para os déficits apresentados.

- AgenteQuatro: encarregado de cadastrar informações no banco de dados depois de certo "aprendizado". A aprendizagem é uma característica forte nos sistemas de agentes. Com a ajuda e as confirmações do AgenteTres, será possível conceber ao AgenteQuatro a capacidade de aprendizado e cadastramento de novos déficits e novos marcadores no banco.

- AgenteServlet: responsável por monitorar e realizar a comunicação do AgenteTres com o chat e com o AgenteUm, centralizando em um único agente a inferência do mecanismo de intervenção do chat com o usuário.

A comunicação entre os agentes está ilustrada na Figura 2. 


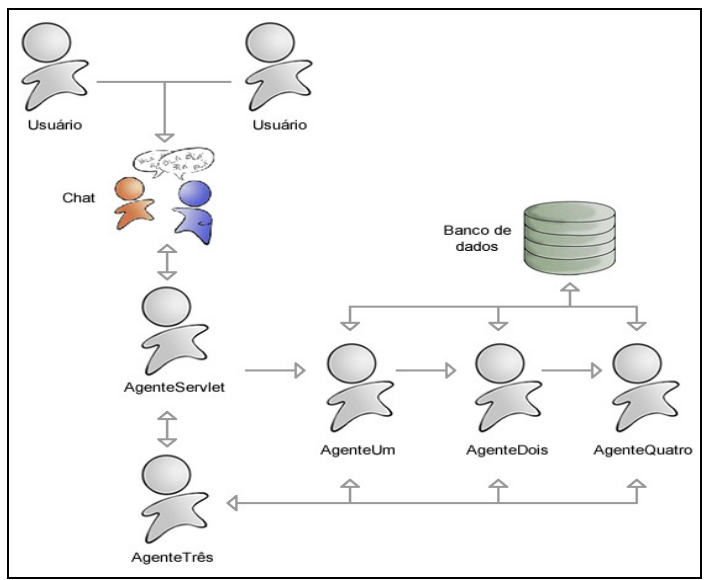

Figura 2. Esquema de Comunicação entre os Agentes

Para a implementação do ambiente proposto estão sendo utilizadas: a linguagem Java, a plataforma de gerenciamento Jade e os padrões FIPA ${ }^{4}$ para a comunicação dos agentes (Figura 3). A tecnologia JADE, Java Agent Development ${ }^{5}$, mostra-se eficiente no suporte, gerenciamento e monitoração do sistema multiagente, principalmente na parte de comunicação entre cada instância de agente. A comunicação, por sua vez, segue os protocolos FIPA para troca de mensagens entre agentes. Um sistema baseado em agentes funciona com agentes autônomos executando determinadas tarefas; solicitando tarefas a outros agentes do sistema; ou até mesmo controlando o nascimento/morte de agentes menores.

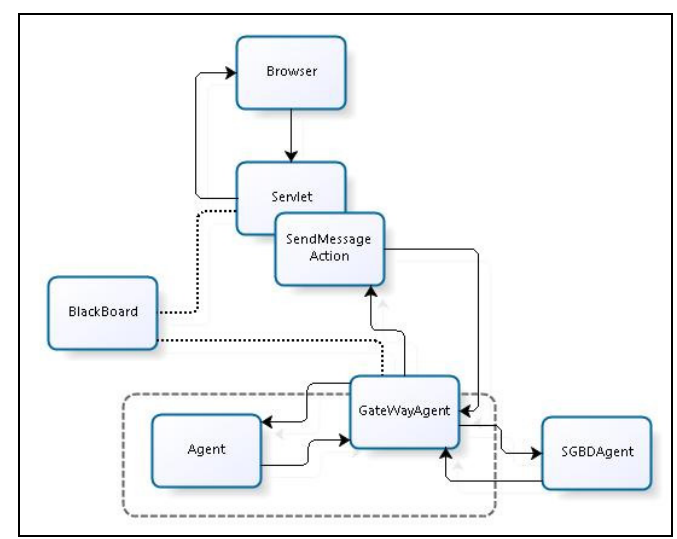

Figura 3. Diagrama de Funcionamento entre o Jade e o chat

Na plataforma, agentes são iniciados através do método $\operatorname{setup()~e~suas~tarefas~são~}$ determinadas por comportamentos. Cada agente recebe, em seu nascimento, um conjunto de dados identificando o serviço prestado e o local de execução de suas tarefas - bem como, possivelmente, conjuntos de ontologias ou outras características

\footnotetext{
${ }^{4}$ FIPA, sigla para The Foundation for Intelligent Physical Agents, é uma organização aceita pela IEEE Computer Society como reguladora de padrões para interação de agentes e sistemas de agentes (http://www.fipa.org/).

5 Desenvolvida durante as pesquisas da Telecom Italia, empresa italiana de telecomunicações disponível no site da Telecom Italia Labs (HTTP://jade.tilab.com).
}

V. $7 \mathrm{~N}^{\mathrm{o}}$ 3, dezembro, 2009 
classificatórias no serviço. Aqui, entende-se como característica classificatória qualquer informação que permita ao agente boot da plataforma identificar capacidades específicas de determinado grupo de agentes numa solicitação por determinado serviço ou método.

Juntamente com as características do serviço, o agente pode receber comportamentos. De forma simplificada, estes comportamentos são os programas a serem executados. A diferença é que essa execução pode vir acompanhada de outros comportamentos do próprio agente ou de outros do sistema. Por isso a grande semelhança e a inevitável comparação de agentes inteligentes com agentes humanos.

A arquitetura de agentes que será utilizada para o desenvolvimento do protótipo será do tipo BDI e para a modelagem será utilizada a técnica UML.

\section{Considerações Finais}

A conversação é um dos elementos da comunicação em que os interlocutores podem interagir e efetuar trocas que acabarão, normalmente, no desenvolvimento cognitivo. Uma conversação não bem sucedida pode caracterizar dificuldades de sociabilização dentro de uma comunidade virtual, gerando, muitas vezes, interpretações equivocadas.

O SMA sendo desenvolvido na CV-Muzar conta com os três primeiros agentes; o mínimo necessário para realizar o estudo. O Agente Quatro, devido a sua complexidade, será desenvolvido posteriormente. Enquanto isso, o cadastro de novas informações sobre marcadores e déficits é feito manualmente.

Os agentes funcionam como assistentes pessoais que auxiliam o usuário em suas mais diversificadas tarefas, nesse caso, eles auxiliam os usuários do bate-papo a interagir com a ferramenta em si e com os outros usuários da sessão, fazendo com que o haja interação e o diálogo se torne atraente e desafiador. Além da mediação do ambiente, é importante que o agente não tire a concentração do usuário no tema debatido, apenas dê algumas dicas e/ou sugestões, fazendo com que o usuário continue com a atenção voltada para o diálogo.

Neste sentido, pretende-se com esta pesquisa, identificar, através da análise dos marcadores conversacionais do chat da CV-Muzar, os déficits de comunicação existentes nos diálogos. Esta identificação será utilizada para criar uma base de conhecimento que proporcionará aos agentes inteligentes uma intervenção, propondo ao usuário formas de compensação. Este método, principalmente através da análise dos marcadores conversacionais, auxiliará os participantes do bate-papo a manterem a interação e, consequentemente, fazer com que esta ferramenta síncrona de comunicação possibilite resultados mais efetivos de aprendizagem.

Agradecimentos. Ao Conselho Nacional de Desenvolvimento Científico e Tecnológico pelo apoio através do Edital MCT/CNPq 15/2007 - Universal e pela bolsa de iniciação científica e à Fundação de Amparo a Pesquisa do Rio Grande do Sul, pela concessão de uma bolsa de iniciação científica. 


\section{Referências Bibliográficas}

De Marchi, A. C. B. (2006) Um ambiente de suporte a comunidades virtuais baseadas em repositórios de objetos de aprendizagem para apoio à aprendizagem informal em museus. Porto Alegre: UFRGS, 2006. 225p. Tese (Doutorado) - Programa de PósGraduação em Informática na Educação, UFRGS, Porto Alegre.

Herring, S. (1996) Posting in a different voice: gender and ethics in CMC. In Ess, C. (Ed.), Philosophical Perspectives on Computer-Mediated Communication, State University of New York Press, Albany.

Lévy, P. (1996) O que é virtual? Ed. 24, São Paulo.

Marcuschi, L. A Análise da Conversação. Série Principios. São Paulo: Ed. Ática, 2006.

Marcuschi, L. A. (2002) Gêneros textuais e ensino. Rio de Janeiro: Lucerna.

Mongoose Techology. (2001) The 12 Principles of Civilization - Guidelines for Designing Interactive Internet Services. Disponível em: <http://www.mongoosetech.com>. Acesso em: 16 ago. 2004.

Orecchini, C. K. (1996) Análise da conversação: princípios e métodos (Conversation analysis: principles and methods). Parábola Editorial.

Rabello, Roberto dos Santos (2008), Interação e Autismo: uso de agentes inteligentes para detectar déficits de comunicação em ambientes síncronos. Exame de qualificação (Doutorando em Informática na Educação) - UFRGS, Porto Alegre.

Recuero, R. da C. (2002) Comunidade virtuais no IRC: o caso do \#Pelotas - Um estudo sobre a comunicação mediada por computador e a estruturação de comunidades virtuais. Dissertação de mestrado, UFRGS, Porto Alegre.

Watzlawick, P.; Beavin, J. H.; Jackson, D. D. (2000) Pragmática da comunicação humana (Pragmatics of human communication). Cultrix, São Paulo.

Wooldridge, M. (2002) Introduction to Multi Agent Systems. Chichester: Wiley. 